\title{
TEOLOGÍA POLÍTICA Y RACIONALIDAD PRÁCTICA
}

Fecha de recepción: 4 de febrero de 2019

Fecha de aceptación y versión final: 24 de abril de 2019

RESUMEN: En el presente artículo desarrollamos una teología política general como condición de posibilidad de cualquier teología política sistemática, libre de las aporías denunciadas en la célebre polémica de 1970. En primer lugar, plantearemos una teología política sistemática capaz de superar las mencionadas aporías. A continuación, expondremos los antecedentes más relevantes de esta crítica de la razón teopolítica centrada en su dimensión práctica. Finalmente concluiremos nuestra investigación mostrando la teoría de la acción aristotélico-escolástica como corolario de esta teología política general.

PALABRAS CLAVE: teología política; praxis; teoría acción; Carl Schmitt.

\section{Political Theology and Practical Rationality}

ABSTRACT: In the present article we develop a general political theology as a condition of possibility of any systematic political theology, free from the aporias denounced after the famous controversy of 1970. First, we will propose a systematic political theology capable of overcoming the mentioned aporias. Next, we will present the most relevant antecedents of this critique of the theopolitical reason focused on its practical dimension. Finally, we will conclude our investigation showing that the Aristotelian-Scholastic theory of action is the corollary of this general political theology.

KEY WORDS: political theology; praxis; action theory; Carl Schmitt.

\footnotetext{
* Universidad Católica San Antonio de Murcia (UCAM): desiderio.parrilla@ gmail.com. ORCID: https://orcid.org/0000-0001-7203-5630 


\section{LAS APORÍAS DE LA TEOLOGÍA POLÍTICA TRAS LA POLÉMICA DE 1970}

Las aporías denunciadas en la polémica de 1970 sobre la «liquidación de toda teología política» determinaron en el ámbito académico la convicción de que la teología política como disciplina sistemática resultaba imposible ${ }^{1}$. Estas aporías se referían a la dimensión práctica de la disciplina. No obstante, las diversas aporías en cuestión derivan en su conjunto de una aporía anterior más general ${ }^{2}$. Esta surge cuando la teología política intenta conciliar dos requisitos aparentemente incompatibles: la perspectiva etic de una teoría científica o filosófica (neutralidad axiológica, imparcialidad, objetividad y racionalidad) y la perspectiva emic de una intervención práctica en política (interés partidista, compromiso para transformar la realidad política desde la fe o la teología $)^{3}$.

«La elección es clara. Y también es precisa la aporía: o bien una hermenéutica política se mantiene decididamente como hermenéutica, pero entonces es impotente para convertirse en política, en el sentido de que un procedimiento hermenéutico, interpretativo [...] no permite integrar la cuestión de la causa del discurso interpretado ni

1 Para un extenso análisis del debate: Michele Nicoletti, Trascendenza e potere: la teologia politica di Carl Schmitt (Brescia: Morcelliana, 1990). Carlo Galli, "Le teologia politische di Carl Schmitt”, en Democrazie e religioni, ed. M. Ruggenini (Roma: Donzelli, 2012), 334-347. Montserrat Herrero, "On Political Theology: The Hidden Dialogue between C. Schmitt and Ernst H. Kantorowicz in The King's Two Bodies", History of European Ideas vol. 41, n. 8 (2015): 1164-1177. Cf. Montserrat Herrero, The Political Discourse of Carl Schmitt. A Mystic of Order (Lanham: Rowman \& Littlefield, 2015).

2 Adolfo González Montes, "Las aporías de la teología crítica: Sobre algunos estudios recientes”, Salmanticensis Vol. 29, Fasc. 3 (1982): 425-442. Karl Lehmann, "Aporías actuales de la teología política", Selecciones de Teología 38 (1971): 174. Robert Spaemann, "Teología, profecía y política. Hacia una crítica de la teología política”, Selecciones de Teología 38 (1971): 182-183. Marcel Xhaufflaire, La teología política (Salamanca: Sígueme, 1974), 90-97.

${ }_{3}$ La distinción entre perspectiva emic y etic resulta crucial para el desarrollo sistemático de cualquier disciplina. En sus estudios de determinadas culturas el lingüista y antropólogo Kenneth Lee Pike estableció la distinción entre: 1) el punto de vista interno, emic, donde se adopta la perspectiva de los sujetos que participan en esos contenidos culturales; y 2) el punto de vista exterior, etic, que describe los contenidos culturales como un observador externo que no comparte la vivencia de los sujetos involucrados. 
pasar realmente a la fase de transformación y de creación de la realidad [...]; o bien la hermenéutica se convierte efectivamente en política y práctica, en el sentido de que la praxis se convierte en su punto de referencia real, pero entonces no le queda ya más salida posible que desaparecer en cuanto hermenéutica» ${ }^{4}$.

Esta aporía ya había sido enunciada de forma embrionaria por el propio Johann Baptist Metz: «¿No se pasa al campo de la ética en su intento de comprender la teología como una orientación del actuar? ¿No echa a perder con ello, tanto el asunto de lo político como el de la teología?» ${ }^{5}$. El desafío de la aporía fue aceptado tanto por los partidarios $^{6}$ como por los detractores ${ }^{7}$ que debatieron en 1970 acerca de la posibilidad de la teología política como disciplina sistemática. El teólogo Trutz Rendtorff consideraba esta paradoja como el «fondo de saco» de toda la reflexión teológico-política ${ }^{8}$. El dilema en cuestión reside en que la teología dogmática o fundamental, de tipo eclesial, al implantarse en la praxis social produce un efecto contraproducente para ambas instancias. Al convertirse en política, la teología dogmática se disuelve en la praxis social o entorpece esa praxis con sus dogmas. Si la doctrina teológica pasa a ser motivo de acción, la propia acción política sufre el peligro de someterse a sus planteamientos ideológicos. «Está legítimamente permitido pensar que es ése precisamente el callejón sin salida en donde desemboca la hermenéutica que pretende ser la "teología política" de Metz»9 .

4 Michel Schoonbrood, "Praxis social y referencia a Jesucristo", en Práctica de la Teología Política, Marcel Xhaufflaire et al. (Salamanca: Sígueme, 1978), 81.

5 Johann Baptist Metz, "La teología política en discusión”, Selecciones de Teología 38 (1971): 110s

6 «O bien su teología es política y entonces es una doctrina que legitima prácticas politizadoras del cristianismo [...], proceso que comportaría la desaparición de todo elemento específico cristiano, o bien su teología no es política, no es sino la exposición de una fe que no debe ser afectada por la política, y usurpa ilegítimamente la calificación de política», Xhaufflaire, 83.

7 «Todo el error de la teología política está en ser teología y no un proyecto político de movilización de los cristianos por medio de motivaciones razonables en el plano político», Robert Spaemann, Crítica de las utopías políticas (Pamplona: EUNSA, 1980), 131.

8 Trutz Rendtorff, "Politische Ethik oder "politische Theologie”?", en Diskussion zur politischen Theologie, ed. Helmut Peukert (Mainz-München, Matthias Grünewald, 1969) 217-230.

9 Schoonbrood, 81. 
Los intentos de superar estas aporías fueron muy diversos. Para escapar a este Scila y Caribdis, Jacob Taubes se situó a la misma distancia de cualquier partidismo emic, teocrático o cesaropapista, oponiéndose a ambos por igual en una postura que definió como «teología política negativa ${ }^{10}$. Reinhart Maurer desarrolló este concepto y propuso una distinción neta entre la «teología política negativa» que se ocupaba de estudiar la legitimidad de cualquier teología política y la «teología política positiva», que no se refiere a la teología política estudiada sistemáticamente, sino a la teocracia o «religiones políticas» en terminología de Erik Voegelin ${ }^{11}$. El término «teología política negativa» recuperaba la noción anterior de "teología política crítico-negativa», piedra angular de la «nueva teología política», como negación de la privatización y el apoliticismo religioso, con que Johann Baptist Metz pretendió superar la objeción aporemática planteada por Hans Maier durante el debate $^{12}$.

En 1969 Karl Rahner enunció como alternativa a la teología política su proyecto de una «teología práctica» que incluiría el momento negativo-crítico y el momento positivo-constructivo ${ }^{13}$. Pretendía emancipar la disciplina de las aporías introducidas por el «catolicismo político» de Carl Schmitt sin dejar de potenciar la crítica contra la tecnocracia y el cientificismo sobre la sociedad contemporánea. Esta postura guardaba similitudes con la «hermenéutica teológico-política» de Dorothee Sölle ${ }^{14}$ y heredaba, paradójicamente, los planteamientos de Hans Barion, quien diferenciaba entre la «teología política» y la "política teológica ${ }^{15}$. La primera englobaba la totalidad de procedimientos de crítica ejercidos por la sociedad religiosa sobre la sociedad política. La segunda abarcaba los procedimientos del poder temporal para

10 Jacob Taubes, La teología politica de San Pablo (Madrid: Trotta, 2007), 117.

11 Reinhart Maurer, "Chiliasmus und Gesellschaftsreligion. Thesen zur politischen Theologie", en Religionstheorie und Politische Theologie, ed. Jacob Taubes (Paderborn: Fink Verlag, 1983), 1:77-84.

12 Hans Maier, "Politische Theologie, Einwände eines Laien”, en Diskussion zur politischen Theologie, ed. Helmut Peukert (Mainz-München, Matthias Grünewald 1969), 11.

13 Karl Rahner, “¿Qué es teología política?”, Arbor (1976): 245ss.

14 Dorothee Sölle, Teología política (Salamanca: Sígueme, 1972), 65.

15 Hans Barion, "Weltgeschichtliche Machtform? Eine Studie zur Politischen Theologie des II. Vatikanischen Konzils", en Epirrhosis: Festgabe C. Schmitt (Berlin: Duncker \& Humblot, 1968), 13-59. 
apropiarse de los recursos eclesiales y justificar así sus políticas seculares. El discípulo de Carl Schmitt suspendía de este modo cualquier aporía posible al precio de negar la posibilidad misma de la disciplina, concluyendo que cualquier teología política era ilegítima, bien por ser ajena a la tradición eclesiástica, bien por ser simplemente inexistente.

Otros autores buscaron una vía intermedia hablando de la «teología de lo político» en vez de teología política, como una teología genitiva asociada a la doctrina social de la Iglesia. Egbert Höflich restringía esta «teología de lo político» a una prolongación emic de la teología pastoral, referente a «cuestiones de la política o de la responsabilización ético-social de los creyentes ${ }^{16}$. Finalmente, Clodovis Boff recuperó esta «teología de lo político», sin renunciar por ello a la posibilidad una disciplina racional y objetiva etic acerca de las relaciones entre lo político y lo religioso ${ }^{17}$. Salvo esta rara excepción, la mayoría de las propuestas erradicaban los síntomas sin emitir un diagnóstico, como si matando al perro se hubiera entendido como curar la rabia.

\section{TEOLOGÍA POLÍTICA SISTEMÁTICA COMO SUPERACIÓN DE LA TRADICIÓN HEREDADA}

A nuestro modo de ver, la matriz de las aporías planteadas entonces reposaba sobre un postulado compartido por todas las partes en conflicto. De modo que el anatema intrasistémico podría disolverse transformando el esquema que sostuvo la querella y sustituyéndolo por otro diferente. Este planteamiento alternativo disuelve la confusión entre el plano emic y el plano etic que está en el origen del consabido paralogismo. Las aporías surgen precisamente en esta confusión de planos que deben ser diferenciados convenientemente, pues la fundamentación de una teología política sistemática libre de anomalías requiere despejar este bloqueo autorrefutante. La alternativa en cuestión consiste básicamente en admitir una doble consideración de la disciplina en su

16 Egbert Höflich, "Heilsverkündigung als politische Gewissensbildung, Eine Antwort auf Hans Maiers Polemik gegen die politische Theologie", Frankfurter Hefte 12 (1969): 851. 844.

17 Clodovis Boff, Teología de lo político. Sus mediaciones (Salamanca: Sígueme, 1980), 50-169. 
conjunto, distinguiendo entre: A) la teología política general y B) la teología política especial ${ }^{18}$.

La teología política general (Theopolitica maior) se ocupa de la composición orgánica de la disciplina y hace las veces de una «teología política fundamental». La composición orgánica de la teología política nos suministra la estructura lógica que cierra el campo y los elementos a los que obedecen sus contenidos. Estos elementos que definen la composición orgánica de la teología política son los siguientes: los principios, los géneros y las reglas de composición entre géneros. Los principios siguen una clasificación trimembre: pluralismo, incompatibilidad e incomunicación de los géneros. Los géneros de teología política derivan de las reglas de composición entre la institución religiosa (I) y la institución política (E) y resultan ser tres: cesaropapismo, teocracia y pluralismo, incluyendo todas las especies posibles de cada género supremo ${ }^{19}$. Los esquemas lógicos de composición que rigen entre los géneros se corresponden con los funtores algebraicos de la reducción y la yuxtaposición, aunque cada uno de estos tipos admite matices inherentes a cada funtor $^{20}$. Así la reducción puede ser inmediata (absorción) o mediata (subordinación) y la yuxtaposición puede ser a su vez continua (generando el monismo) o discontinua (generando el dualismo o el pluralismo). El hispanismo es una forma de pluralismo, basado en la disyunción débil, mientras que el cesaropapismo y la teocracia son formas de monismo, fundados en la reducción entre sociedad política y sociedad religiosa ${ }^{21}$.

18 Para el desarrollo completo de esta propuesta remito a Desiderio Parrilla Martínez, Estatuto de la teología política como disciplina sistemática, Tesis doctoral, 2018, 61-137.

19 Jacob Taubes elaboró su reflexión teopolítica consciente del pluralismo inherente a este campo. Teoría de la religión y teología política fue el título genérico de esta investigación que aglutinaba tres volúmenes temáticamente diferenciados: El príncipe de este mundo. Carl Schmitt y sus secuelas (1983), Gnosis y política (1984) y Teocracia (1987). El género cesaropapista se recoge en Taubes como «tipo representación» en El príncipe de este mundo, que entiende al soberano político como representante de Dios en la tierra. El género hierocrático es conceptuado por Taubes como el «tipo teocracia» en su obra homónima Teocracia: el modo de institucionalizar la soberanía de Dios sobre la tierra directa y no representativamente. El «dual sovereignty» (según la designación de Rodney Needham) en su obra Gnosis y politica se hace cargo del dualismo en yuxtaposición discontinua que nosotros hemos denominado "pluralismo».

${ }^{20}$ Gustavo Bueno, Cuestiones cuodlibetales sobre Dios y la religión (Madrid: Mondadori, 1989), 347-375.

${ }^{21}$ Gustavo Bueno, España frente a Europa (Barcelona: Alba Editorial, 1999), 231-238. 
El pluralismo manifiesta la morfología de incompatibilidad que subyace a cualquier composición lógica entre los géneros y explica el hecho histórico de que no haya un solo tipo de teología política, sino una pluralidad de tipos ${ }^{22}$.

La teología política especial (Theopolitica minor) se encarga de la composición técnica del campo y abarca la labor de las diversas ciencias y técnicas sobre los productos de cultura objetiva (documentos, reliquias, archivos, monumentos) donde ha quedado estabilizada la composición orgánica de la teología política. Incluye tanto las ciencias humanas (historiografía, derecho), como las ciencias positivas (arqueología, ecdótica, paleografía, filología), así como las doctrinas teológicas y filosóficas implicadas en el campo (doxografía). Postulamos una realimentación constante entre lo que llamamos teología política general y teología política especial, vale decir, entre el estudio de un modelo general válido para toda teología política posible y el estudio de cada caso particular de teología política dado históricamente. Tanto los principios, como los géneros y los esquemas de composición se obtienen de la composición técnica de la teología política. Son las diversas ciencias positivas implicadas en la conceptualización del campo teopolítico, aquellas que segregan los elementos por cuya mediación surgen a su vez los principios derivados (o mediatos) de la composición orgánica del campo ${ }^{23}$. Gracias a la composición técnica se establecen los principios de la composición orgánica. Pero la composición orgánica establecida a través de las ciencias y técnicas es la que rige la construcción del campo donde está inmersa la composición técnica.

Desde una perspectiva estructural y no histórico-genética podemos atender a las reglas de composición entre los términos de la teoría teológico-política: la institución política (E) y la institución religiosa (I). Los pares de conceptos (E,I) mantienen una oposición lógica sui generis (que no es de contrariedad, ni de contradicción, ni de mero relativo) que puede estudiarse en el marco de la conexión diamérica. Esta conexión

${ }^{22}$ Gustavo Bueno, Primer ensayo sobre las categorías de las ciencias políticas (Logroño: Biblioteca Riojana, 1991), 34-89.

${ }_{23}$ Esteban Peña Eguren, La filosofía política de Guillermo de Ockham. Relación entre potestad civil y potestad eclesiástica (Madrid: Encuentro, 1994), 19-22. Carlos Corral Salvador, Teología política. Una perspectiva histórica y sistemática (Valencia: Tirant, 2011), 227-234. Ernst Hartwig Kantorowicz, Los dos cuerpos del rey: un estudio de teología política medieval (Madrid: Akal, 2012), 324-325. 
se puede formular según las alternativas típicas de cualquier sistema de functores: yuxtaposición de I y E; reducción de I a E, o de E a I; fusión de I y E en un tercero; o articulación de I y E en terceros. La oposición teológica Hombre/Dios (o institución religiosa/institución política) conlleva diferentes formas de composición, que fluctúa entre las siguientes reglas con rasgos políticos característicos:

A) Alternativa de la subordinación (reducción, en el límite asintótico) de la institución política (E) a la institución religiosa (I): $\mathrm{I} \rightarrow \mathrm{E}$ $(1,0,1,1)$, origina el monismo teocrático y el Teologismo políti$c o$, del que el "agustinismo político» es su forma típica en la tradición cristiana y, en la tradición islámica, el wahabismo suní, la hierocracia chiíta o el salafismo yihadista.

B) Alternativa de la subordinación (reducción, en el límite asintótico) de la institución religiosa (I) a la institución política (E): $\mathrm{E} \rightarrow \mathrm{I}$ $(1,0,1,1)$, que origina el monismo cesaropapista pero también el Antropologismo político o Humanismo trascendental de Hegel, Feuerbach, Comte o Marx, hasta las doctrinas laicistas de la secularización de Hans Blumenberg.

C) Alternativa de la yuxtaposición entre institución política (E) y la institución religiosa (I), donde cabe distinguir dos posibilidades:

1) Conjunción entre institución política (E) a la institución religiosa (I): $\mathrm{E} \wedge \mathrm{I}(1,0,0,0)$, origina el dualismo, representado por la posición del tomismo medieval, la postura de las democracias cristianas, o algunos autores de la Public Theology. Esta última alternativa resulta muy problemática desde el punto de vista de su validez, pero además encubre el conflicto entre las alternativas A) y B) con una propuesta mixta o ecléctica.

2) Disyunción entre institución política (E) a la institución religiosa (I): introduce a su vez dos posibilidades en un dilema cornudo:

i) Disyunción fuerte o exclusiva entre institución política (E) a la institución religiosa (I): EWI $(0,1,1,0)$, puede ser reducida al monismo de A) y B).

ii) Disyunción inclusiva, débil o alternativa, entre institución política (E) a la institución religiosa (I): EvI $(1,1,1,0)$, origina tanto: 1) el monismo y el dualismo, si consideramos la composición de los términos haciendo abstracción de su conexión con el entorno, la cual será de incompatibilidad 
contra terceros; como 2) el pluralismo, si tomamos en consideración la incompatibilidad que ambos términos compuestos establecen con otras alternativas del entorno.

Tanto la composición técnica como la composición orgánica arrojan, por tanto, una pluralidad de especies agrupadas en torno a tres géneros generalísimos: teocracia $(\mathrm{I} \rightarrow \mathrm{E})$, cesaropapismo $(\mathrm{E} \rightarrow \mathrm{I})$ e hispanismo $(\mathrm{E} \vee \mathrm{I})$. Estos principios se nombran respecto a su origen histórico-genético de procedencia, pero son términos abstractos que podrían nombrarse como términos exentos de connotación histórica de la siguiente manera: género $\mathrm{C}$, género $\mathrm{T}$ y género $\mathrm{H}$, como géneros teopolíticos de la historia universal. Porque cada uno de los géneros deriva de la regla de composición que los origina, no de los materiales históricos donde se realizaron por primera vez los géneros posibles o sus especies.

Estos tres géneros generalísimos constituyen el núcleo esencial de la teología política. La reducción lógica, como absorción o fusión $(\rightarrow)$, es la regla de composición que genera el monismo, que abarca dos géneros: el cesaropapismo $(\mathrm{C}=\mathrm{E} \rightarrow \mathrm{I})$ y la teocracia $(\mathrm{T}=\mathrm{I} \rightarrow \mathrm{E})$. En la composición orgánica, la yuxtaposición (E,I) se puede interpretar como conjunción $(\mathrm{E} \wedge \mathrm{I})$ o como disyunción débil inclusiva $(\mathrm{E} \vee \mathrm{I})$. De la conjunción brota el dualismo, mientras que de la disyunción alternativa brota el pluralismo, que es coextensivo y de igual intensión que el género hispano $(\mathrm{H})$. El modelo bizantino es un modelo de cesaropapismo canónico. El modelo carolingio se define como una teocracia (o hierocracia) ejemplar. El modelo Imperial Hispánico implica una relación dialéctica de dos poderes (el Trono y el Altar), una disyunción inclusiva donde el poder político y el poder espiritual vivifican la sociedad civil mediante una relación no armónica, sino polémica, basada en la incompatibilidad frente a terceros.

Etienne Gilson propuso en 1939 clasificar las especies de teología política del Antiguo Régimen, derivadas de estos tres géneros supremos, del siguiente modo ${ }^{24}: 1$ ) monistas partidarios de la supremacía de la institución religiosa sobre la sociedad política. Incluye hierócratas, papalistas, curialistas y decretalistas. 2) Monistas partidarios de la hegemonía

${ }^{24}$ Etienne Gilson, Dante et la philosophie (París: Vrin, 1986), 200. Esteban Peña Eguren, La filosofía política de Guillermo de Ockham. Relación entre potestad civil y potestad eclesiástica (Madrid: Encuentro, 1994), 20-22. Bayona Aznar, El origen del Estado laico desde la Baja Edad Media (Madrid: Tecnos, 2009). 
del poder político sobre el poder eclesiástico. Abarca regalistas, imperialistas o legistas. 3) Dualismo como tercera vía: ambos poderes guardan una relación de igualdad sin que ninguno se subordine al otro poder. Cada uno tiene su propia esfera de dominio soberano, bien sea espiritual o temporal. Cuando un ámbito entra en conflicto con otro, la vía media propone solventar armónicamente, en función del bien común, esta superposición de esferas.

Por su parte, el profesor Antonio García y García presenta cuatro grandes teorías ${ }^{25}$ : (1) monismo hierocrático: cualquier poder se comunica de Dios al papa y a la Iglesia, quienes encomiendan el poder temporal al príncipe, pero conservando un poder directivo sobre la sociedad política (Egidio Romano, Egidio Spiritualis de Perusa, Lamberto Guerrici de Huy, Alfonso Álvarez Guerrero, Nicolás de Cusa, Alejandro de Viterbo, Álvaro Pelagio, Agustín Triunfo, Summa Monacensis, Alano Anglico, etc. $)^{26}$. (2) Dualismo eclesiástico: ambos poderes subsisten de modo autónomo con su propia esfera de dominio. No obstante, la autoridad espiritual predomina sobre el poder temporal cuando la sociedad política atenta gravemente contra la ley natural (poder indirecto y dualismo de Gelasio I, Franciscus Gracianus, Roberto Bellarmino, Inocencio III y IV). (3) Monismo laico: cualquier norma jurídica positiva queda pendiente del poder temporal, incluyendo la religiosa que subsiste como una forma de delegación (Marsilio de Padua, Guillermo de Ockham, Felipe IV de Francia, Antonio de Rosellis). (4) Dualismo laico: postula la autonomía de ambos poderes, pero en caso de conflicto se impone el poder político.

Carlos Corral Salvador afina más la clasificación jurídica de los diversos monismos y dualismos ampliándola a las innovaciones del nuevo régimen. Este autor establece una atinada taxonomía de las transformaciones que el monismo y el dualismo sufren desde la modernidad hasta nuestros días ${ }^{27}$. Tras la paz de Westfalia el agravamiento de la ruptura en la unidad política del imperio universal acaba con las aspiraciones del monismo, el dualismo y la diarquía. En opinión de este autor, la

25 Antonio García y García, "Sacerdocio, Imperio y Reinos", en Cuadernos Informativos de Derecho Histórico Público, Procesal y de la Navegación (Barcelona: PPU, 1987), 509-540.

${ }_{26}$ Michael Wilks, The Problem of Sovereignty in the Later Middle Ages: The Papal Monarchy with Augustinus Triumphus and the Publicists (Cambridge: Cambridge University Press, 2008), 118-148.

27 Corral Salvador, 227-234. 
bifurcación más decisiva que introduce la modernidad es la establecida entre el monismo hierocrático (o sistema de la potestad directa) y el dualismo inherente al sistema de la potestad indirecta ${ }^{28}$.

Estos tres géneros (cesaropapismo, teocracia, hispanismo) y sus respectivas especies son propios del Antiguo Régimen y la cristiandad tradicional premoderna. No obstante, estos géneros evolucionaron tras la crisis modernista y los modelos secularizados del nuevo régimen resultan avatares teopolíticos suyos. Así, por ejemplo, el modelo cesaropapista de origen bizantino $(\mathrm{E} \rightarrow \mathrm{I})$ se manifiesta en las doctrinas modernas derivadas de la Revolución francesa y el imperio napoleónico, la Kulturkampf y la socialdemocracia del Programa de Erfurt (1891), la «teología del desarrollo tecnocrático», o previamente Le Sillon de Marc Sangnier o la Acción Francesa de Charles Maurras según la condena de Pío X. El proyecto de ley propuesto inicialmente por Émile Combes para la Ley de separación de la Iglesia y el Estado de 1905 es un caso paradigmático de este cesarismo de nuevo régimen. La asociación Patriótica Católica China fundada en 1957 presenta similares rasgos cesaropapistas. El modelo teocrático de origen carolingio estaría incorporado al «occidentalismo político» o al «europeísmo» de Alcide De Gasperi, Konrad Adenauer, Robert Schuman y Jean Monnet, con los ideólogos precursores del Zentrum y la democracia cristiana italiana. Esta modalidad carolingia extraoficial es practicada por la Iglesia católico-romana junto con un cierto hispanismo moderado inherente a los Pactos de Letrán (1929) que son el origen del modelo concordatario actual, la teología política oficial del Vaticano. La teocracia reverdeció con el carlismo y el «nacionalcatolicismo», pero también con la «teología de la liberación» y actualmente rebrota solo «sobre el papel» en doctrinas como la «ortodoxia radical» de John Milbank y su entorno como Catherine Pistock o William T. Cavanaugh. La teocracia musulmana sin embargo regresa con fuerza a través de proyectos como el Estado Islámico Universal propuesto por Daesh, los talibanes, Al-Qaeda y el islam wahabita y salafista. También advertimos una recuperación de la teocracia en la capa nematológica del imperio norteamericano con propuestas como el fusionismo, el teocapitalismo, la Teología del Dominio (R. J. Rushdoony) o el reconstruccionismo cristiano. Otros ejemplos aislados de hierocracia actual serían el ejército de resistencia del señor

${ }_{28}$ Para una síntesis erudita de estas innovaciones dualistas: Pedro Jesús Lasanta Casero, "La doctrina canónica anterior al concilio. Sobre la potestas ecclesia in temporalibus”, Ius canonicum 34, n. ${ }^{\circ} 68$ (1994). 595-615. 
de Joseph Kony, el BJP en la India o el programa de los monjes budistas en Myanmar y Sri Lanka.

Desde esta perspectiva sistemática la teología política puede reconstruirse como aquella disciplina que se encarga del estudio racional y objetivo de la dimensión metapolítica de los Estados ${ }^{29}$, abarcando el encaje completo de las ramas y capas del poder político con las instituciones asociadas a lo sagrado, tanto en sus dimensiones prepolíticas, geopolíticas, civiles y supraestatales. Aunque asociada en su origen a la religión, la dimensión metapolítica objeto de estudio incluye sus posteriores desarrollos secularizados, sean políticos, filosóficos o de otro género. Tanto en el nivel general como en el especial, esta disciplina opera bajo el principio de objetividad de la perspectiva exterior etic. Pero si uno se adentra en el interior de la teología política especial puede introducir el factor práctico, tomando partido por alguna de las alternativas posibles, dando paso a la perspectiva emic. Este posicionamiento introduce un elemento operatorio dirigido por la prudencia que no existe en el interior de la teología política general. Esto no significa en modo alguno que en el nivel especial de la disciplina se suspenda la objetividad o la racionalidad inherente a la perspectiva etic, en contra de lo afirmado por la tradición heredada. Pero hay que reconocer que, en caso de actuar como sujeto operatorio que toma partido por alguna de las teologías políticas particulares, el razonamiento práctico preside esta reflexión.

El estudio metódico de la teología política general y la investigación crítica de las teologías políticas especiales informará racionalmente el curso práctico de nuestras elecciones en el conjunto de la disciplina. Sin embargo, cada teología política especial contiene su propia regla práctica de aplicación y reclama un comportamiento distinto. En consecuencia, cada teología política particular tiene la virtualidad de educar sujetos morales muy diferentes, conformando caracteres distintos según los hábitos teológico-políticos adquiridos ${ }^{30}$. En este sentido debe entenderse la aportación de Wolfhart Pannenberg en la discusión sobre la teología política ${ }^{31}$. Pannenberg advirtió que una ética cristiana es

${ }^{29}$ Gustavo Bueno, "En torno al rótulo 'Meta-política'”, El Catoblepas, n. ${ }^{\circ} 128$, octubre Cfr. Rótulo "Metapolítica” [http://filosofia.org/ave/002/b039.htm] (revisado: 05/11/2018).

30 Johann Baptist Metz, Teología del mundo (Salamanca: Sígueme, 1971), 159.

31 Wolfhart Pannenberg, "Geschichtstatsachen und christliche Ethik. Zur Relevanz geschichtlich-politischer Sachfragen für die christliche Ethik, 2. Veröffentlichung," 
y debe ser no solo una ética del «orden» sino también del «cambio» ${ }^{32}$. Pannenberg concedía que ya no procede argumentar políticamente partiendo de enunciados teológicos como sucedía antes de la Ilustración. Sin embargo, toda argumentación política supone un particular ángulo de visión: el neoliberal, el marxista o el católico no interpretan de la misma manera las situaciones políticas. En ese nivel hermenéutico de la reflexión política, las categorías teológicas pueden tener un significado político ${ }^{33}$.

En consecuencia, la solución de las aporías prácticas planteadas pasa por el pluralismo teopolítico que sostiene la teología política general que proponemos. Esta organización teórica nos permitirá posteriormente adoptar una perspectiva emic desde fuera del sistema de clasificación, tomando partido por una alternativa frente a las demás, no por prejuicio o espíritu de partido, sino por considerarla más potente racionalmente. De esta manera, esa intervención práctica no será inmotivada o irracional sino sostenida por un sistema de deliberación a cuyo servicio se pone la perspectiva etic. Se trata de constituirse en causa sibi, como agente racional y ordenador (etic), y no meramente como un agente intermedio y ordenado (emic). De esta manera se salvaguardan ambas perspectivas (emic y etic) sin incurrir en la consabida aporía de la tradición.

Fuera de este planteamiento sistemático seguiría vigente la aporía de la razón práctica de la teología política, sin posibilidad de escapar de ella. La perspectiva emic consiste entonces en el manual de instrucciones de uso interno para los adeptos de una determinada confesión religiosa o ideología política, en lo concerniente a la relación entre el Estado, o diversos Estados, con respecto a su grupo de referencia, tanto a nivel institucional como teórico-práctico, ya sea en forma de derecho eclesiástico del Estado, sociología de las instituciones, teología moral o ética teológica referida al Estado. Es decir, mero «realismo político» o simple «realismo teológico político» ${ }^{34}$.

en Diskussion zur politischen Theologie, ed. Helmut Peukert (Mainz-München: Matthias Grünewald, 1969), 231-246.

32 «La teología política es, en este caso, la hermenéutica cristiana específica de una ética política concebida como ética del cambio». Johann Baptist Metz, Dios y tiempo. Nueva teología política (Madrid: Trotta, 2002), 53. Jürgen Moltmann, Teología política. Ética política (Salamanca: Sígueme, 1984), 105.

33 Pannenberg, 235.

34 Jürgen Moltmann, El Dios crucificado (Salamanca: Sígueme, 1977), 400ss. Cfr. Siegfried Wiedenhofer, Politische Theologie (Stuttgart: Kohlhammer, 1976). Jan Milic 
Porque efectivamente, en la perspectiva emic, hay que incluir también la realpolitik (o realteopolitik) de las Iglesias, sectas o tradiciones religiosas (y hasta parareligiosas). A este respecto, dentro de la perspectiva emic cabe incluir también una postura límite propia de la tradición cristiana según la cual la teología política es una disciplina del corpus teológico y, en consecuencia, debe ser considerada como una rama o aplicación de la teología al mundo político, sin perjuicio de que exista una historia de las diversas doctrinas teopolíticas, como parte de la historia de las ideas, y la historia de las formas políticas.

«La concepción contemporánea de la teología política se ha originado en la política y no en la teología, de tal manera que ha resultado propuesta en primer lugar por escritores políticos y, de forma especialmente llamativa, como es sabido, por Carl Schmitt, en relación con el problema de la secularización tanto del mundo como de la teología misma. En otros términos, fue planteada como tema político e histórico, y no teológico; y aun esto, desde el punto de vista político. En cualquier caso, no cabe duda que la teología política se desprende, como una consecuencia posible, de las relaciones entre la religión y la política» ${ }^{35}$.

Esta posición sincretista es sostenida actualmente por los profesores Carlos Corral Salvador y Dalmacio Negro, en la línea propuesta por Álvaro d'Ors, quienes distinguen entre la historia de la teología política y la teología política propiamente hablando ${ }^{36}$. Según Carlos Corral, la historia de la teología política es la aplicación de conceptos teológicos al mundo político (el planteamiento de Carl Schmitt) pero la teología política sería una parte de la teología fundamental que deduce consecuencias políticas. Para salvaguardar los derechos de la teología tradicional, frente a las innovaciones de la teología política que se aceptan desde Carl Schmitt, el profesor Carlos Corral se acoge al criterio tradicional escolástico según el cual la teología dogmática (y por deducción la teología política) sería una ciencia etic porque es un sistema de proposiciones derivado de principios.

Lochmann, Perspektiven politischer Theologie (Zürich: TVZ Verlag, 1971).

35 Corral Salvador, 37.

${ }^{36}$ Carlos Corral Salvador y Dalmacio Negro Pavón, “¿Es de verdad posible hoy una Teología Política?”, Revista General de Derecho Canónico y Derecho Eclesiástico del Estado-IUSTEL 17 (2008): 1-7. Dalmacio Negro: “¿Por qué no la teología política?”, en Estudios sobre la Centessimus Annus, coord. F. Fernández Rodríguez (Madrid, AEDOS-Unión Editorial, 1992), 249-294. 
Según este planteamiento ecléctico, la teología política, y no solo la historia de la teología política, sería ciencia etic en sentido estricto, dado que comparte con la teología dogmática la condición de ciencia en sentido aristotélico, según el criterio de los segundos analíticos, porque aporta conocimiento verdadero y necesario a partir de unos primeros principios autoevidentes, los axiomas que sirven de premisas a esta ciencia particular. En el caso de la teología dogmática las premisas de este silogismo científico son las verdades de fe suministradas por la ciencia divina. Las conclusiones de la teología política se deducirían mediante razonamiento a partir de estas verdades sobrenaturales reveladas. Pero de nuevo estamos en la perspectiva emic del participante, en este caso del creyente, de modo que la sistematicidad de la disciplina queda socavada desde la base. Pues arranca de premisas partidistas y no de conclusiones que es legítimo, o incluso necesario, aceptar como término de un razonamiento etic, pero no como petición de principio.

«La teología política, ni como doctrina sistemática ni como historia de la misma, es idéntica a las relaciones entre la religión y la política. Tampoco son lo mismo la política religiosa o las relaciones entre la Iglesia y el Estado u otra forma de lo político y la teología política. Esta última sólo se refiere a la teología, a fin de cuentas, a una disciplina intelectual, como fuente de los conceptos e ideas políticos, o como los límites de la política desde una perspectiva religiosa. Por esto mismo, la teología política, al igual que cualquier otra rama de la teología, no puede ser independiente de la religión, puesto que la fe es siempre la fuente o causa de la teología » ${ }^{37}$.

Esta postura a caballo entre el planteamiento emic y una perspectiva propiamente etic, supone un paso hacia delante en lo que se refiere al rigor científico y la sistematicidad de la disciplina dentro de la tradición cristiana. Pero incluso esta postura sincretista ha suscitado recelos desde sus inicios ${ }^{38}$. En la actualidad este enfoque sigue siendo una cuestión candente y es el centro del debate sobre el papel de la religión en las sociedades secularizadas ${ }^{39}$. Su gran limitación nos parece, sin embargo, residir en que no llega a cumplir ninguno de sus cometidos.

Por un lado, no resuelve en el ámbito mundano de la práctica política cuál es la teología política idónea o con qué protocolos o procedimientos

37 Corral Salvador, 41.

38 Hans Maier, Kritik der Politischen Theologie (Einsiedeln: Verlag, 1970), 18-19.

39 Corral Salvador, 37. 
administrativos legales implantarla en las sociedades contemporáneas. Por otro lado, tampoco aporta la claridad y distinción de ideas que serían necesarias en el ámbito académico acerca de los contenidos mismos de esa teología política. Dado que este era el objetivo principal de la perspectiva sincrética no cabe concebir un fracaso mayor ${ }^{40}$.

Tal vez obedezca a este doble fracaso lo aporético de las discusiones que esta perspectiva suscita. Carlos Corral Salvador ponía de manifiesto las dificultades de esta perspectiva adoptada por él mismo: «Como constatación conclusiva, la realidad es que todavía no existe una teología política sistemática. No obstante, desde el punto de vista católico y siguiendo la propuesta de Álvaro d'Ors, creemos que no hay una barrera infranqueable para una teología política. Por ello nos hemos propuesto esa tarea tan arriscada como compleja de acometer, siquiera, una aproximación a una teoría general de teología política desde la teología cristiana como tal. Audaces fortuna iuvat» ${ }^{41}$.

\section{ANTECEDENTES DE LA TEOLOGÍA POLÍTICA SISTEMÁTICA DESDE LA RAZÓN PRÁCTICA}

El orden gnoseológico, sobre el que se asienta el fenómeno de las relaciones entre institución religiosa y política, se traduce por medio de una Theopolitica maior: un sistema estructurado de lugares lógicos que establecen las condiciones que son absolutamente comunes a todos los enunciados de la disciplina. La especialización de la teología política presupone la fijación de un material temático que comporta los elementos pertinentes - los elementos que pertenecen esencialmente- al universo de discurso del campo. Pero el desarrollo de esta «teología política fundamental», que es la teología política general, sirve también como regla general plausible de la acción práctica, como instrumento regulativo de la vida individual y social. Funda así decisiones que pueden orientar

40 El propósito de la «nueva teología política» también radicaba en «definir de nuevo la relación entre la religión y la sociedad, entre la Iglesia y el dominio público social, entre fe escatológica y la práctica social», Johann Baptist Metz, Teología del mundo (Salamanca: Sígueme, 1970), 139-179 (144).

${ }^{41}$ Carlos Corral, "Una Teología Política, ¿es actualmente posible?”, [en línea: http://blogs.periodistadigital.com/carloscorral.php/2008/06/17/p172468] (Revisado: 6/3/2018). 
la acción humana mediante una deliberación razonable. En esta perspectiva de la intervención, los temas que forman el universo teopolítico quedan organizados en una arquitectura razonable, pero sobre todo hacen posible una dimensión pública del cálculo racional. La fuerza de la teología política no se reduce al contenido de verdad que posee, sino que se manifiesta con mayor potencia en el razonamiento como componente de la acción humana.

Esta organización sistemática es decisiva porque permite cumplir uno de los objetivos tradicionales de la disciplina. Como teología política sistemática posibilita una acción práctica también sistemática, bien sea moral o política. La posibilidad práctica de la teología política no resulta ya, a partir de ahí, nada distinto de su posibilidad epistémica. En realidad, ambos niveles deben considerarse como partes de un único proceso. Si, por un lado, declaramos haber conseguido establecer el sistema, por otro lado, reconocemos definitivamente, en el interior del sistema, el reconocimiento de la teología política como órgano fundamental de la acción práctica. Pues de lo que se trata es de disponer de un instrumento de control que determina los límites de la disciplina con referencia a la «tasa de verdad» de las proposiciones que intervienen en los procesos de elección.

De este modo adoptamos una perspectiva objetivista no solo según el punto de vista formal sino también desde la perspectiva material de los contenidos. En los contenidos de la teología política general quedan excluidos en la medida de lo posible todos los componentes subjetivos y operatorios, asociados al partidismo, la confesionalidad o el interés pragmático. En este sentido reconocemos el gran valor de la obra de Carl Schmitt que prolongó la labor de Hegel en su pretensión de fundar una disciplina teórica sin la intervención de elementos psicologis$\operatorname{tas}^{42}$. En Carl Schmitt el binomio "amigo-enemigo ${ }^{43}$ se convierte en un

${ }^{42}$ Este objetivismo es el que permite distinguir en Hegel sus "Lecciones de filosofía de la historia universal" frente a sus "Lecciones de filosofía de la religión", donde el primero sería un tratado sistemático y etic de teología política y el segundo un tratado de fenomenología (o psicología evolutiva) de la conciencia religiosa, donde el planteamiento emic resulta inevitable.

43 «El núcleo de lo político no es la enemistad, sino la distinción entre amigo y enemigo», Carl Schmitt, Teoría del partisano (Madrid: Trotta, 2013), 90. «En las cambiantes agrupaciones amigo-enemigo de la historia universal, la teología puede convertirse políticamente en un asunto tanto de la revolución como de la contrarrevolución», Carl Schmitt, Teología política (Madrid: Trotta, 2009), 69. 
tecnicismo o categoría politológica que pierde todos sus componentes psicológicos o zoológicos tan presentes, sin embargo, en Thomas Hobbes $^{44}$. En lo referente al estricto campo teológico político Carl Schmitt abandonó el planteamiento tradicional que presupone una perspectiva psicologista, porque funda sus contenidos en materiales suministrado por la vivencia psíquica o la simple etología.

Enrique Dussel subraya la importancia para la teología política de este planteamiento objetivista impuesto por Hegel y continuado por Schmitt frente a cualquier tipo de subjetivismo. Para Dussel el subjetivismo de la autoritas consiste en el hecho de querer fundar la teología política en la psicología de la voluntad ${ }^{45}$, reduciendo el campo teopolítico al campo del sujeto psicológico, incluso del sujeto etológico, clausurando la posibilidad objetiva de un sujeto que se pueda desenvolver - como agente racional- bajo las reglas de una disciplina objetiva. La teología política fundada en las nociones psicologistas de autoridad (o legitimidad) permite crear condiciones de control sobre el individuo, pero no permite la reflexión crítica sobre un campo de conocimiento, que incluye no solo una forma de teología política especial sino muchas otras alternativas. De este modo el descubrimiento de la verdad del campo en cuestión queda imposibilitado desde la base, desde el momento mismo en que se identifica esa teología política especial con la totalidad de la disciplina en general, originando el más nefasto de los paralogismos ${ }^{46}$. Resulta, por tanto, inaceptable fundar, o disolver, una teología política sistemática desde un planteamiento psicopolítico o biopolítico, como pretenden autores como Giorgio Agamben o Roberto Esposito.

Carl Schmitt estableció el principio de objetividad para la disciplina cuando convirtió la potestad en el fundamento del poder político y teológico-político, negando a la autoritas realidad independiente respecto de

44 Julien Freund, La esencia de lo político (Madrid: Editora Nacional, 1968), 615-620. En coincidencia con Carl Schmitt, hace notar que la enemistad política y, correlativamente, la guerra son específicamente distintos a la vez de la enemistad privada y de la querella, disputa o venganza de particulares, así como de la violencia interindividual. Abunda en esta perspectiva técnica de la enemistad política en su obra: Julien Freund, Sociología del conflicto (Madrid: Ministerio de defensa, 1995), 71.

45 Enrique Dussel, Política de la liberación II (Madrid: Trotta, 2009), 46-66.

${ }^{46}$ Karl Lehmann, "Die politische Theologie: Theologische Legitimation und gegenwärtige Aporie”, en Essener Gespräche, IV, (Münster: Verlag, 1969), 126ss. 
la potestas ${ }^{47}$. Para Carl Schmitt la autoridad procede de la potestad como fuerza hegemónica. De este modo el objetivismo se impone en la forma y en el contenido y se evacúan todos los componentes subjetivistas tanto en la composición orgánica como en la técnica. La perspectiva etic adoptada por Hegel y retomada por Schmitt nos permite superar los paralogismos originados en la teología política a causa del subjetivismo tanto en la reflexión teórica de la disciplina en general como en la confusión de planos que ocurre cuando confundimos este nivel general con alguna de las teologías políticas especiales dadas en la historia. Cuando el objetivismo se convierte en principio de la composición técnica entonces las aporías de la razón teológico-política cesan de manera definitiva ${ }^{48}$.

En su respuesta a la vieja teología política de Schmitt, el teólogo Johann Baptist Metz puso en el centro de la nueva teología política la dimensión práctica hasta el punto de considerar la disciplina como una «apología práctica de la teología», es decir, una teología fundamental cuyo fundamento es la acción práctica. Este interés práctico estaba presente en la recuperación de la vieja teología política cuando el propio Carl Schmitt la recuperó para intervenir políticamente en la crisis de la República de Weimar. La réplica de Erik Peterson comprende también esta dimensión práctica en su intento por deslegitimar la ReichTheologie. Leo Strauss y Eric Voegelin hicieron lo propio durante la Guerra Fría. Y lo mismo cabe decir de cualquier teología política que se precie de serlo, como los teólogos de la liberación pusieron de manifiesto, o en la actualidad los neoconservadores tras la caída de la URSS.

47 «La dictadura es para Cortés no menos legal que la legitimidad; la pregunta práctica de siempre es, si la Dictadura surge de arriba o de abajo o, diríamos hoy, de la derecha o de la izquierda, por encima o sujeta a ella [la legalidad]; sin embargo, la pregunta sobre la legitimidad de la dictadura [se da] cuando para salvar a la sociedad [no basta sino] la dictadura; y como resultado de eso mismo se produce entre nosotros esta discusión sobre 1849 o cualquier otra cuestión, es decir, la legitimidad. [Conclusión:] la dictadura es un gobierno legítimo como cualquier otro», Carl Schmitt, Glossarium. Aufzeichnungen Der Jahre 1947-1951 (Berlin: Dunker und Humboldt, 1991), 49. «Es por su afición al estado hobbesiano, que Schmitt no entiende la diferencia entre autoridad (saber reconocido) y potestad (poder reconocido)», Álvaro d'Ors, "El Glossarium de Carl Schmitt", en Estudios sobre Carl Schmitt, ed. Dalmacio Negro Pavón (Madrid: Fundación Cánovas del Castillo, 1996), 32. Juan Fernando Segovia, "Schmitt y Álvaro d’Ors: Una inspiración ad modum recipientis", Fuego y Raya 11 (2016): 101-124.

48 Adolfo González Montes, Teología política contemporánea. Historia y sistemas (Salamanca: PUPS, 1995), 142-147. 
Bajo el ascendente de Metz, la teología de la liberación insistió en esta naturaleza práctica y crítica de la teología política proponiendo una nueva concepción de la teología como reflexión crítica sobre la práctica eclesial y social en general. En cuanto teoría específicamente teológica de la práctica eclesial la teología, como ciencia de la fe, investigaba y reflexionaba al servicio de la prolongación actualizadora de la historia de la realidad cristiana, realizada dentro y a través de las comunidades de Dios $^{49}$. Para los teólogos de la liberación la teología política partía de la fe y a ella regresaba en una tentativa de entendimiento crítico, procurando estar al servicio de la aplicación personal y colectiva del aquí y del ahora. Se trataba en definitiva de una exigencia de comprensión a la altura de los tiempos «respecto de los condicionamientos económicos y socioculturales de la vida y la reflexión de la comunidad cristiana $»^{50}$. La teología política, como teoría de una práctica determinada, «no podía ser sino una crítica de la sociedad y de la Iglesia en tanto que convocadas e interpeladas por la palabra de Dios $»^{51}$. La teología de la revolución (José Comblin, Helmut Gollwitzer), previa a la teología de la liberación, fue también eminentemente práctica hasta el punto de legitimar la violencia revolucionaria. Pero esta práctica revolucionaria no era justificada desde la ética sino desde la teología, por lo que la teología de la revolución era una teología política en sentido estricto ${ }^{52}$.

Gustavo Gutiérrez en su esfuerzo de sistematización no prescindió de las funciones clásicas de la teología como sabiduría y como saber racional. Pero las incorporó a una hermenéutica política del Evangelio con el objeto de esbozar un concepto nuevo de teología: una teología en perspectiva latinoamericana, como reflexión crítica de la praxis histórica. Su punto de partida fue una reflexión de la fe de cariz socioanalítico que venía dada por la práctica histórica de la sociedad y de la Iglesia políticamente comprendida. Según Hugo Assmann lo que estaba en juego era la identidad crítica de la teología más que su diferencia con el resto de las ciencias críticas de lo real. Entre estas y la teología «existe una

${ }^{49}$ Edward Schillebeeckx, El mundo y la Iglesia (Sígueme: Salamanca, 1970), 221.

${ }^{50}$ Gustavo Gutiérrez, Teología de la liberación. Perspectivas (Salamanca: Sígueme, 1972), 34.

51 Schillebeeckx, 223.

52 Helmut Gollwitzer, Crítica marxista de la religión (Madrid: Marova, 1971), 155. Pablo Dabezies y Benoit A. Dumas, Teología de la violencia (Salamanca: Sígueme, 1970), 28-29. 
diferencia que se expresa, cuando la teología de la liberación pretende encarar esta praxis de los cristianos como corporificación histórica de su fe, a la luz del Evangelio, a la luz de la revelación $»^{53}$. Para Assmann la teología de la liberación dejaba claro, por una parte, que el sentido de la fe estaba inmerso en esta praxis inevitablemente, so pena de no haber verdadera teología política. Pero, por otra parte, no bastaba con la fe y sus testimonios históricos para distinguir una buena teología política de otra menos buena, pues se hacía necesario una presencia de la fe en la práctica social y política que no fuera ingenua. Y en este sentido la teología política requería el inevitable recurso a las ciencias humanas ${ }^{54}$.

En este punto de inflexión que supuso la «teología política de la liberación» la fe se manifestaba como praxis. La fe, en vez de ser mera contemplación especulativa de la verdad, se erigía en la realización práctica de esa verdad. Assmann lo explicaba en los siguientes términos: "Se declara el fin de toda logia que no sea logia de la praxis. Se rompe el hechizo verbal de la palabra eficaz. Se denuncia la gratificación sustitutiva del decir la verdad, en la medida en que no se apoya en el hacer la verdad ${ }^{55}$. La idea de verdad se equiparó entonces con la noción de la praxis verdaderamente eficaz, pero no solo en sentido pragmático-utilitario, o consecuencialista, sino con un alcance auténticamente ontológico. Con la teología de la liberación, la teología política sufrió una mutación definitiva. La disciplina experimentó un desplazamiento respecto de su centro de gravedad, que pasó desde la teoría a la praxis, lo cual implicaba «la simultaneidad, tanto del aspecto humano, como del aspecto eficaz de la praxis». Esto incluía tanto la práctica interior del sujeto reflexivo (sea individual o colectivo), como la práctica exterior, el éthos y el nómos. Pero también incluía la reflexión que surge dentro de la misma práctica, «en la proximidad máxima del nivel estratégico-táctico de la acción humana, sin lo cual esta reflexión no sería conciencia crítica y conciencia proyectual, revisión y prospección de la praxis en cuanto tal» ${ }^{56}$.

Con esta mutación histórica la teología política había adquirido un nuevo rasgo para su patrimonio genético: no puede existir teología política sistemática sin incluir en el sistema la formulación de sus dimensiones

${ }^{53}$ Hugo Assmann, Teología desde la praxis de la Liberación (Salamanca: Sígueme, 1973), 61 .

54 Assmann, 62.

55 Assmann, 181.

56 Assmann, 89-90. 
prácticas. Esta práctica eficaz en el ámbito social y político no era, sin embargo, mera razón de Estado, ni mera razón de Iglesia ${ }^{57}$. No se reducía a una pragmatización de la disciplina, pero conducía necesariamente a una revisión del concepto de fe y de teología. Para Assmann la fe es simultáneamente ortodoxia y ortopraxis. No optaba por la ortopráctica contra la ortodoxia, sino que entendía esta realizando su verdad en aquella. En esta ortopraxis no solo se transforman estructuras positivas, normas convencionales o dimensiones técnicas propias de lo factible, sino que se transforman las dimensiones inmanentes asociadas a la eticidad, como por ejemplo el desarrollo virtuoso de las potencialidades humanas, a nivel individual y social. Para Gustavo Gutiérrez la conversión al prójimo implicaba esta doble capacidad de transformación, interior y exterior, individual y colectiva, personal e institucional ${ }^{58}$.

Assmann advierte que la interpretación práctica de la fe no pretende alcanzar una simple mejora en la aplicación de la verdad. Esta es una interpretación minimalista que no recoge en todo su alcance la concepción de la fe como práctica. La consecuencia que se sigue de esta innovación es mucho más radical, puesto que «no hay una verdad fuera de los eventos históricos en los cuales los seres humanos actúan como agentes. [...] Porque no hay conocimiento aparte de la acción, del proceso de transformación del mundo mediante la participación en la historia ${ }^{59}$. El devenir histórico desencadenado por la praxis determina este encaje entre teoría y praxis, como principio que constituye la verdad histórica. El descubrimiento de la praxis, y situarlo en el centro de la reflexión, hace imposible entenderla como un lugar teológico que se limita a favorecer el conocimiento de la verdad. La teología no puede reducirse a facilitar la manifestación de la verdad mediante la acción, porque la praxis se ha convertido en su fundamento, invirtiéndose el esquema teológico tradicional. Verum est factum, como afirmó Vico. Assmann reconoce el ascendente del marxismo sobre este planteamiento: la verdad surge en los procesos de producción material de la historia. Se incurre

57 Hugo Assmann advierte que esta metodología no debe confundirse con la teología pastoral asumida por Heinz Schuster o Karl Rahner: «Mientras estos localizan casi exclusivamente la acción intraeclesiástica, eje de convergencia del reformismo postconciliar, la teología de la liberación disloca este eje hacia la acción liberadora dentro de la conflictividad del mundo en sentido fuertemente político», Assmann, 60.

58 Gustavo Gutiérrez, 250-265 (sobre todo cap. 10).

59 José Míguez Bonino, La fe en busca de eficacia: una interpretación de la reflexión teológica latinoamericana de liberación (Salamanca: Sígueme, 1977), 114. 
una naturalización de la verdad, tanto a nivel epistemológico como ontológico, a causa del materialismo que preconiza.

Esto no significa que la concepción de la fe como práctica histórica quede reducida en la teología de la liberación a mera acción de transformación social, políticamente mediada y conducida por criterios inmanentes del proceso transformador. Sin embargo, hace esa misma fe obsoleta e innecesaria dado que el análisis desideologizador postulado por la aplicación de la fe se realiza igualmente sin ella, aplicando meramente la mediación socioanalítica de las nuevas ciencias humanas. De manera que la hermenéutica de la fe resultó prescindible para desarrollar el método de aproximación a la realidad histórica de la vida humana. Esto fue lo que permitió con Enrique Dussel que la «teología de la liberación»se transformara en "filosofía de la liberación», dado que los contenidos de la fe se volvieron innecesarios, incluso superfluos, para instituir una teología de lo político. La propuesta de Clodovis Boff, que rechaza cualquier praxeología antiteórica y antiteológica, reconoce este dialelo que surge al pasar de la verificación práctica de la verdad a los elementos teoréticos que sustentan esta verificación. Reconoce además que el origen de este círculo vicioso que deja fuera la fe reside en el planteamiento de Karl Marx en la tesis XI sobre Feuerbach ${ }^{60}$.

A nuestro entender el mérito de la teología de la liberación consiste en haber llevado a sus últimas consecuencias el intento de emprender una acción práctica en teología política sin haber establecido previamente esa teología política como disciplina sistemática. Pero sus anomalías son aplicables, mutantis mutandis, al activismo inherente a sus adversarios neoconservadores y teocapitalistas ${ }^{61}$. Tanto en uno como en otro caso, la consecuencia indeseable para los teólogos (perspectiva

${ }^{60}$ Clodovis Boff, Teología de lo político. Sus mediaciones (Salamanca: Sígueme, 1977), 157ss.

${ }^{61}$ Moltmann somete a crítica la razón teológica del Estado norteamericano que conduce al mesianismo de una nación, la cual objetivaría su destino histórico en su liderazgo mundial. Por la misma razón se enfrenta con la ideología de la unión soviética que llevó al socialismo hacia la rusificación y el despotismo asiático. En uno y otro caso ve el teólogo nuevas formas de religión política. Jürgen Moltmann, "Crítica teológica a la religión política", en Ilustración y teoría teológica. La Iglesia en la encrucijada de la libertad moderna. Aspectos de una nueva teología política, J. B. Metz, J. Moltmann y W. Oelmüller, eds., (Salamanca: Sígueme, 1973) 11-45. Jürgen Moltmann, "El sueño americano", en Teología política, ética política (Salamanca: Sígueme, 1987), 65-78. 
emic) es que la fe cristiana se vuelve innecesaria. Pero desde una perspectiva etic la situación no es mejor, dado que la teología política queda sin establecerse como disciplina teórica y se la sustituye por los planes de acción inherentes a las doctrinas neoliberales o neomarxistas.

La teología de la liberación postulaba una nueva manera de hacer teología, más que incorporar temas nuevos al patrimonio teológico tradicional. Esta renovación radical estaba determinada por la teología política y sus implicaciones prácticas, tanto éticas como políticas ${ }^{62}$. La teología de la liberación, afirmó Gustavo Gutiérrez, «no se limita a pensar el mundo, antes bien busca situarse como un momento del proceso a través del cual el mundo es transformado ${ }^{63}$. Respondía de este modo al reto planteado por Marx en la tesis XI sobre Feuerbach a propósito de la filosofía. La propuesta de Hugo Assmann insistía en este enfoque. Esta modificación de la epistemología teológica fue imprecisa en la producción de estos primeros autores, pero tuvo en la obra de Clodovis Boff, Teología de lo político. Sus mediaciones (1976), una elaboración bien definida que agotaba todos los puntos en discusión ${ }^{64}$. Esta obra permitió establecer los logros y las aporías que planteaba la teología política de la liberación. Hasta el punto de que su explicitación epistemológica supuso un punto de inflexión para el movimiento ${ }^{65}$.

Para Clodovis Boff la posibilidad de transformar el medio histórico social por la práctica de la fe requiere la mediación socioanalítica (MSA) en la que dicha práctica se ejerce. Para ello establece la distinción entre la fe (o conciencia de la salvación) de la teología propiamente tal (o conciencia crítica de la salvación) que se constituye mediante la aplicación del método socioanalítico a la conciencia de la fe. La teología deviene ciencia solo si llega a ser teología crítica en la operación consciente de

${ }^{62}$ Adolfo González Montes, Teología política contemporánea: historia y sistemas (Salamanca: PUPS, 1995), 142-145.

63 Gutiérrez, 40-41.

64 «[Clodovis Boff] es quizás el más sistemático trabajo teológico que intenta asumir el marco teórico de Althusser. Es una práctica teórica sumamente rigurosa en la subsunción del marxismo francés de la década del 70. Muestra cómo puede usarse un marco categorial marxista en una teología estrictamente cristiana de lo político». Enrique Dussel, “Teología de la liberación y marxismo”, en Mysterium liberationis. Conceptos fundamentales de la teología de la liberación, eds. Ignacio Ellacuría y Jon Sobrino (Madrid: Trotta, 1990), 1:130.

${ }^{65}$ Para una síntesis sistemática de esta cuestión: Tony Mifsud, "Clodovis Boff: Teología de lo político (nota)”, Teología y vida 22 (1981): 275-280. 
estos presupuestos gnoseológicos. Pero esto solo es posible mediante la mediación socioanalítica (MSA) aplicada a la fe. Para ejercer esta MSA el teólogo debe utilizar el instrumental analítico que le proporciona las ciencias humanas, especialmente aquellas que permiten al teólogo acceder a la dimensión política de toda práctica histórico-social, como exige la práctica de la fe. En consecuencia, el teólogo solo llega a ser propiamente tal cuando ejerce la única teología científica que es la teología política. En este nivel superior se alcanza la conciencia crítica que puede desvelar los elementos ideológicos que se filtran en la conciencia acrítica de la fe ${ }^{66}$. Por otra parte, Boff se muestra receloso con la función de mediación hermenéutica (MH) que la fe dogmática pudiera desempeñar históricamente en la teología política, tanto en la teoría como en la práctica. Boff defiende la necesidad de someter a crítica desde la mediación socioanalítica (MSA) cualquier mediación hermenéutica (MH) de la fe, con independencia de que esta concluya en posiciones cesaropapistas, teocráticas o de una teonomía participada. Solo el análisis de la mediación socioanalítica (MSA) puede penetrar metodológicamente en los elementos ideológicos que encierra toda mediación hermenéutica, sea cristiana o no.

El mérito de Clodovis Boff es haber presentido la diferencia entre la composición técnica y la composición orgánica de la teología política. Su mediación socioanalítica (MSA) no llegaría a ser una composición orgánica estricta del campo, pero sería una distinción embrionaria de la composición técnica respecto de las ciencias humanas implicadas en la teología política especial. La MSA resulta un atisbo de nuestra tesis según la cual los principios de la composición orgánica derivan de los hechos tematizados por las diversas ciencias positivas en la composición técnica del campo. Otro gran acierto es haber identificado cualquier mediación hermenéutica ( $\mathrm{MH})$ de la fe dogmática con algunas especies históricas de la teología política especial y nunca con la composición orgánica misma. De este modo las diversas formas cristianas de teología política se convierten en ocurrencias contingentes y provisionales de la teología política especial, sin que ninguna de ellas, ni ninguna otra posible, pueda identificarse con la teología política considerada en su conjunto como disciplina.

${ }^{66}$ Boff, 168. 
Como podemos advertir, en su recurso a la mediación socioanalítica (MSA) Boff intenta evitar las «aporías prácticas de la razón teológico-política» que confunde la composición orgánica con la técnica. Aunque no haya llegado a captar ni formular ninguno de los dos niveles de manera explícita, su propuesta barrunta la necesidad de liberar el razonamiento teológico político de estas aporías que se originan al confundir ambos niveles en un mismo plano. Pretende establecer así una teología política general como disciplina etic, ejercida de forma objetiva y racional por observadores externos, libre de las interferencias de tipo emic que puedan introducir los participantes de las diversas teologías políticas especiales.

Sin embargo, tampoco es verdad que Clodovis Boff cumpla con esta pretensión de elaborar un análisis de la teología política general estrictamente etic. Ya que el análisis de la mediación socioanalítica (MSA) está constituido desde una perspectiva emic dependiente de la epistemología del materialismo histórico y dialéctico. Si Boff hubiera sido enteramente coherente con su planteamiento debería reconocer que en último término solo ha formulado una teología política especial de corte marxista, dado que esta epistemología está en la base de sus premisas ${ }^{67}$. Esta teología política marxista es la que evacúa la fe cristiana de la teología política general, pero es también la que impide instituir una teología política general sin incurrir en un paralogismo de otro tipo. Sustituir el marxismo por el cristianismo no impide la generación del paralogismo mencionado cuando se identifica la teología política en general con una de sus especies, tomando la parte por el todo. Por esta razón la mediación socioanalítica (MSA) no logra establecer la composición general de la disciplina como sería preceptivo para un planeamiento etic. Además, la aporía se agrava desde la perspectiva emic ya que se pretende haber establecido esta composición general de la disciplina a partir de una especie (el «demopapismo teocrático» ${ }^{68}$ ) solo porque la especie anteriormente

${ }^{67}$ «Después de Marx se hace imposible teologizar como antes en lo relativo a los problemas sociales», Boff, 55.

68 Acuñamos el neologismo «cesarismo demopapista» componiendo dos aportaciones fundamentales de Gustavo Bueno y Peter Sloterdijk a la teología política contemporánea. El primero calificaba a la «teología de la liberación» como un «demopapismo» en Gustavo Bueno, "Cuestión 9. Teología de la liberación", Cuestiones cuodlibetales sobre Dios y la religión (Madrid: Mondadori, 1989), 353. Del segundo tomamos prestado el genial quiasmo de «biregno papocesarista» para caracterizar la teología política occidentalista de los EE. UU., en Peter Sloterdijk, Esferas (Madrid: Siruela, 2004), 2:683-693. 
sostenida por la Iglesia (la teocracia tradicional de potestad indirecta) ha perdido su prestigio, tratando de beneficiar al nuevo candidato con el valor de una doctrina que estaba de moda cuando la obra se escribió (el socialismo humanista).

La distinción que Boff hace entre una criteriología pística (de orden existencial) y una criteriología teológica (de orden epistemológico) más que alcanzar una solución, supone el reconocimiento de este rotundo fracaso. La criteriología teológica de Boff se ocupa de «las reglas de la práctica teórica del teólogo», pero esta epistemología teológica depende de la fe como principio cognoscitivo. «Consideramos a la epistemología como una función de la teología y a la teología como una función de la praxis de la fe. Tal es el sentido de aquella célebre máxima de Agustín, que repitió luego toda la escolástica: Huic scientiae tribuitur illud, tantummodo quo fides saluberrima gignitur, nutritur, defenditur, roboratur (De Trinitate XVI, 1. Cfr. T. de Aquino, Sth I, q. I a. 2 sed contra) ${ }^{69}$. Sin embargo, Boff pretende simultáneamente fundar el rigor epistemológico de la teología en un proceso de verificación o control contra todo tipo de ideología, incluida la propia fe en cuanto fides qua, de manera que la fe misma queda excluida de la dimensión epistemológica de la acción. Pero por otra parte, ese análisis riguroso que anula la reflexión teológica depende de una determinada praxeología. Y esta depende del modelo de teoría crítica de la práctica con el que se opera, siendo en el caso de Clodovis Boff la teoría de la acción propia del marxismo y su relación dialéctica entre teoría y práctica ${ }^{70}$. De este modo no solo se hipoteca la reflexión teológica, sino que la neutralidad axiológica y doctrinal desaparece bajo el empuje del partidismo ideológico, según se elija uno u otro modelo de teoría de la acción, bien sea marxista (la teología de la liberación), bien sea marginalista (la teología del desarrollo capitalista). De este modo la teología política se ve libre de ese componente emic del partidismo teológico, pero no alcanza la perspectiva etic puesto que la praxis está determinada desde un partidismo ideológico igualmente emic.

A pesar de estas graves objeciones, la obra de Clodovis Boff tiene la virtualidad de mostrarnos las deficiencias de una razón práctica que no sirve para desenvolverse prudencialmente por el campo de la teología política especial. La exigencia de construir una disciplina general nos

\footnotetext{
69 Boff, 30.

${ }^{70}$ Assmann, 97-98. Enrique Dussel, "Teología de la liberación y marxismo", Cuadernos Americanos 12 (1988): 115-144.
} 
obliga a superar las deficiencias de las ideas marxianas en lo referente a la teoría de la acción práctica. El hallazgo de este objetivismo se inicia con Marx, pero debe ir en contra de Marx e incluso más allá de Marx, como por otro lado ya intuyó Clodovis Boff. Solo formulando una teoría de la acción que supere estas limitaciones podremos desenvolvernos correctamente por la teología política especial sin incurrir de nuevo en las aporías denunciadas en la polémica de 1970. Esta teoría de la razón práctica será acorde con la composición técnica de la teología política como un postulado necesario suyo. No existe otra posibilidad de emitir un juicio práctico para la acción que quiera verse libre de los mencionados paralogismos. Esta teoría de la acción práctica, tanto ética como moral, inherente a una teología política general, y libre de anomalías, nos parece que solo puede ser la tradición precedente, dado que los modos posteriores suponen degradaciones culturales derivadas del rechazo de esa tradición anterior.

\section{LA RAZÓN PRÁCTICA COMO COROLARIO DE LA TEOLOGÍA POLÍTICA SISTEMÁTICA}

La teoría de la acción práctica a la que nos referimos es la tradición aristotélico-escolástica, recuperada en el siglo XX para el ámbito moral (Marta Nussbaum, Philippa Foot, Alasdair McIntyre...). Solo de esta manera podrá cerrarse con la totalidad de sus factores una teología política general como disciplina teórica sistemática ${ }^{71}$. Pero no se trata de reconvertir el eudemonismo en una teología política especial, u organizar desde esta doctrina una teología política general, sino mostrar que la racionalización sistemática de la teología política es inviable si no se integra en una racionalidad práctica que juzga el campo especial de la teología política mediante el consejo, la elección, el imperio y el uso. Es necesario recuperar la totalidad del acto voluntario, y no solo el momento de la decisión, para cerrar la composición orgánica de la teología

${ }^{71}$ Para una exposición detallada de la implicación práctica de la teología política general en el interior de la teología política especial: Desiderio Parrilla, "Teología política y razón práctica en el debate entre Carl Schmitt y Erik Peterson", Carthaginensia n. 67 (2019): 191-210. Ibid., "Ética y acción práctica en el conjunto de una teología política sistemática”, en Homenaje al profesor Urbano Ferrer (Madrid: Encuentro 2019), 33-53. 
política. De lo contrario no se alcanzaría una racionalización completa del sistema, dado que la razón teórica exige la razón práctica, pero esta racionalidad práctica debe incluir aquellos elementos que confieren racionalidad al proceso de deliberación.

La reciente Public Theology supone una alternativa teórica y práctica a este proyecto de una teología política sistemática ${ }^{72}$. Desde nuestra perspectiva, la Public Theology posee el mérito de proponer una teoría de la deliberación racional que supera las limitaciones del decisionismo tradicional. Pero esta propuesta carece de una fundamentación teórica lo suficientemente sólida como para dar respuesta adecuada a los problemas que pretende resolver, dejando sin crítica incluso sus causas últimas. Harold Breitenberg ha organizado la literatura sobre la teología pública conforme a tres aspectos ${ }^{73}$. En primer lugar, las investigaciones de los diversos teólogos públicos y cómo entienden el asunto. En segundo lugar, las discusiones sobre la naturaleza y la identidad de la teología pública. Por último, encontraríamos la «teología pública constructiva», que es la práctica real de la teología pública. Los dos primeros tipos remiten al desarrollo de la teología pública como un campo de estudio racional y académico, mientras que el último es la aplicación práctica de la misma al ámbito mundano.

Desde nuestra perspectiva cabe dirigir dos objeciones principales contra esta influyente y meritoria corriente de pensamiento: a) la Public Theology no ofrece un sistema de coordenadas generales para dar cuenta del resto de doctrinas rivales, sus fundamentos racionales, sus mecanismos genéticos y sus múltiples dicotomías, incluyendo su propia propuesta en el conjunto de un sistema etic de teología política universal; y b), en consecuencia, la Public Theology solo es una teología política especial entre otras, las cuales ofrecen además versiones irreconciliables acerca del pluralismo en la sociedad civil o las relaciones entre las diversas sociedades religiosas y políticas, sin que la Public Theology ofrezca razones para privilegiar su propuesta sobre las alternativas rivales, ya que todas proceden según un particular punto de vista emic.

Nuestro sistema pone de relieve que el pluralismo, lejos de ser un concepto simple o unívoco, se manifiesta como un concepto analógico,

${ }^{72}$ Max L. Stackhouse, "Civil Religion, Political Theology and Public Theology: What's the Difference?”, Political Theology 5 (2004): 275-293.

${ }^{73}$ E. Harold Breitenberg, "To Tell the Truth: Will the Real Public Theology Please Stand Up?", Journal of the Society of Christian Ethics 23, n. 2 (2003): 55-96 (63-64). 
puesto que el pluralismo «se dice de muchas maneras»: hay una pluralidad de modalidades de pluralismo. Efectivamente no es lo mismo el pluralismo específico de la teología política especial que el pluralismo de la teología política general. El primero denota exclusivamente la pluralidad de especies, posibles o reales, que se contienen en los tres géneros supremos de teología política, incluyendo las diversas concepciones de pluralismo que cada una de ellas postula; el segundo denota la pluralidad de estos géneros generalísimos que se funda por principio en las reglas de composición de sus términos y que excluye el monismo o el dualismo como únicos géneros posibles. La Public Theology incurre en un paralogismo donde se toma el todo de la teología política especial por el todo de la teología política general. Confunde el pluralismo como principio trascendental que organiza el campo general de la teología política con el pluralismo que supone la multiplicidad categorial de especies de teología política particular.

Sin embargo, nuestro planteamiento comparte con la Public Theology la convicción de que el pluralismo no es una noción equívoca. La propia Public Theology rechaza que este pluralismo suponga un diferencialismo absoluto entre facciones rivales completamente incomunicadas entre sí como mónadas sin ventanas ${ }^{74}$. El espacio público de la sociedad civil de las democracias occidentales supone para la Public Theology la garantía de esta unidad en la diversidad (y diversidad en la unidad) que armoniza la pluralidad de cosmovisiones sin desembocar en el caos o el conflicto universal. Sin embargo, el criterio organizador racional, y en consecuencia de arbitraje práctico, que suministra la teología política general no existe en la Public Theology. Dicha tarea se confía en esta corriente a una teología política especial en concreto, a saber, la diarquía de poderes de la democracia liberal que pretende ser juez y parte de la sociedad civil. A esta objeción debemos añadir otra más radical dirigida por sus rivales teopolíticos: las democracias capitalistas que postulan el pluralismo como cobertura ideológica de su realteopolitik son, en gran medida, las causantes de los problemas que la Public Theology trata de atajar, dejando por tanto sin atacar las causas que originan estos problemas, tal como denunció en los años 70 la teología de la liberación o actualmente la influyente «teología populista».

${ }^{74}$ Hak Joon Lee, "Public Theology", en The Cambridge Companion to Christian Political Theology, ed. C. Hovey (Cambridge: Cambridge University Press, 2015), 44-65. 
Nuestra propuesta escapa a esta anomalía cuando establece los elementos constitutivos de una teología política general como disciplina teórica sistemática. Estos elementos definen la composición orgánica de la teología política como disciplina con campo propio. En su dimensión práctica la teología política general ofrece una teoría de teorías, capaz de establecer el mapamundi completo de la realidad asociada a su ámbito. De este modo reorganiza desde la composición orgánica los materiales suministrados por la composición técnica a fin de establecer una teología política especial no solo coherente sino también verdadera, libre de las diversas distorsiones, falsificaciones y aporías de la que puede ser víctima. Pero además supone un criterio electivo fundamental para el juicio práctico que no sea ingenuo o acrítico, tanto individual (en su vertiente ética) como colectivo (en su aspecto político).

En este sentido se cumple el objetivo práctico que ha perseguido la teología política del siglo XX, pero sin incurrir en ninguna de las aporías suscitadas en su reformulación. La teología política mundana, cuyas ideas están disueltas por el mundo, envuelve a los sujetos y les suministra criterios directivos para la acción. Esta teología política mundana no es sino la totalidad de especies de teología política que se mantienen vigentes en ciertas coordenadas espaciotemporales, la teología política especial vigente en esa región del mundo. La teología política general que ofrecemos propone una teología política académica capaz de dirigir el juicio práctico sin incurrir en las limitaciones mundanas que acompañan al uso precrítico (o acrítico) de la razón.

La teología política mundana (o especial) hace las veces de mores o costumbres que pueden ser racionalizadas mediante la conveniente intervención correctiva de la teología política académica (o general). Las normas étnicas, los ortogramas consuetudinarios y los planes políticos conformados según esta teopolítica mundana, pueden ser depurados de sus componentes espurios, extrayendo mediante la reflexión académica las estructuras esenciales que realmente gobiernan el campo en cuestión. Pero esta verdad teórica no se agota en sí misma dado que está inserta en la necesidad de una verdad práctica, habida cuenta de que esa corrección de naturaleza teórica corrige a su vez la propia acción práctica que llevan a cabo los sujetos históricamente implicados como agentes libres.

En este sentido la teología política general implica una dimensión moral de primer orden, ya que muestra los principios y elementos 
constituyentes de las mores de cada teología política especial. La teología política general permitirá discernir entonces no solo las acciones que pueden realizarse dentro de cada una de las especies, sino que nos pondrá en condiciones de movernos y operar entre todas y cada una de las opciones que definen el campo de la composición técnica. De este modo se abandona definitivamente el planteamiento emic, aun cuando se opere desde alguna de las opciones de teología política especial. Pues se procede de un modo crítico considerando la totalidad del campo sin ceñirlo a una parte del mismo. Aunque la acción práctica pueda operarse desde una de las especies no se incurre en las aporías de la razón teológico-política. La composición orgánica que revela la teoría general de la disciplina permite moverse de forma coherente según la opción teopolítica preferida por el agente moral. Pero también permite considerar de forma sinóptica la totalidad del campo de manera imparcial y objetiva, sin ser víctima de los consabidos errores lógicos que limitan la comprensión y la acción práctica subsiguiente.

Nos gustaría insistir en la virtualidad de la teología política general para discernir entre cada una de las teologías políticas especiales y su grado de moralidad. Sin una teología política general no puede darse este juicio práctico. Si permanecemos exclusivamente en el terreno de la teología política especial no solo resultan inevitables las aporías que malogran la razón teórica, sino que además carecemos de criterios para realizar una deliberación ajustada al objeto de elección, lo cual arruina también la eficacia de la acción práctica. Nos quedamos sin razones para elegir una opción mejor que otra, pero también perdemos la capacidad de cartografiar la totalidad del territorio en que estamos inmersos y en el que necesariamente nos desenvolvemos. Incluso aunque no optásemos por ninguna opción preferente frente a las demás, seguiríamos perdidos y desorientados al carecer de un mapa del espacio que atravesamos o, lo que es peor, por poseer uno que fuera del todo falso.

En todo caso, sin esta teología política general el proceso mismo de la voluntad libre se malogra desde la base. Resulta de la mayor importancia este hecho: no puede haber silogismo práctico ni acción libre, ni por tanto acto moral en el ámbito teopolítico, si no se establece previamente el marco general de una teología política sistemática. Desde los principios que determinan esta composición orgánica se concluye que la mejor elección moral solo puede realizarse desde el pluralismo teopolítico, puesto que este pluralismo es el que abre, y mantiene completamente abierto, el 
abanico de posibilidades del campo. Solo el pluralismo nos ofrece este panorama íntegro para obtener la mejor deliberación informada, sin distorsiones ni deficiencias. En este sentido asumimos que una teología política general como la que ofrecemos rompe con los planteamientos monistas o dualistas de toda la teología política precedente, pero también con una visión simplista y acrítica del mismo pluralismo. Este pluralismo trascendental permite cumplir el programa teórico de una teología política sistemática. Pero también reintroduce el proceso de deliberación en la acción práctica de la disciplina, interviniendo con el cálculo racional en medio de la pluralidad de especies teopolíticas que lo constituye.

Como puso de relieve Carl Schmitt en la teología política tradicional (tanto cristiana como no cristiana) siempre ha prevalecido un planteamiento unilateralmente decisionista. A nuestro entender, la ausencia de una teología política sistemática ha sido la responsable de este decisionismo dominante. La razón es bien sencilla: si se carece de criterios de juicio para sostener la deliberación racional, esta se suspende y la decisión se convierte en la cuestión central del arbitrio, por no decir la única cuestión pertinente. $\mathrm{El}$ «dilema de Böckenförde » ${ }^{75}$ solo podría ser disuelto adecuadamente en el contexto del pluralismo que proponemos, con una teología política sistemática que fortalece no solo la capacidad de decidir sino también la deliberación que sostiene esa decisión. Solo en la medida en que poseamos una disciplina sistemática, ordenada y completa, del campo teopolítico podremos realizar deliberaciones prácticas dentro de ese ámbito de la realidad.

Resulta crucial poseer una teología política general para realizar deliberaciones concretas y tomar decisiones acertadas hic et nunc. Creemos que esta carencia ha sido la responsable de que en la historia de la teología política haya prevalecido el decisionismo sobre la deliberación, dado que la teología política se reducía a la perspectiva del conflicto emic entre facciones rivales. El pluralismo de la teología política general garantiza que esta deliberación pueda llevarse a cabo para sostener el curso y el cuerpo de un campo que no puede sino funcionar desde un núcleo esencialmente pluralista.

Por otro lado, esta naturaleza partidista que define el acto deliberativo de la teología política no implica que nos movamos en una perspectiva

75 «The liberal, secularised state is nourished by presuppositions that it cannot itself guarantee» Wolfgang-Ernst Böckenförde, State, Society and Liberty: Studies in Political Theory and Constitutional Law (New York: Berg, 1991), 45. 
enteramente emic, dado que la teología política general nos suministra el panorama etic completo en que cabe realizar semejante elección. Pero, sobre todo, los elementos de la composición orgánica de esta teología política general ponen en nuestro conocimiento los límites de todas y cada una de las «tomas de partido» que cabe adoptar en la teología política especial. La perspectiva etic de la teología política general nos advierte de las aporías que perturban nuestra capacidad de tomar partido cuando optamos por alguna alternativa monista o dualista. Pero a nuestro entender la consecuencia práctica más interesante de la teología política general reside en el hecho de que adoptar una perspectiva pluralista (no ingenua) es el único modo de mantener un planteamiento etic, racional y objetivo, en los procesos de deliberación y elección práctica. A esta conclusión no llegamos por una arbitrariedad irracional, ni por adoptar un espíritu de partido (partinost), ni por una concesión al «anarquismo epistemológico», sino obligados por las exigencias derivadas de una teología política sistemática.

El desenvolvimiento de un individuo, o un grupo o una institución, informado por el dominio de la teología política general garantiza, por tanto, la posesión de un criterio teórico que puede regir el proceso del acto voluntario tanto elícito como imperado del mejor modo posible. La propuesta académica que denominamos teología política general permite tanto a nivel individual como colectivo establecer un proceso de deliberación en las mejores condiciones a fin de intervenir en la realidad social y política circunstante. En las circunstancias particulares el sujeto moral puede recurrir a la teología política general como criterio de elección óptimo, en virtud de su saciedad explicativa, su necesidad y completitud. Este sujeto moral puede ser individual (un hombre concreto) o colectivo (una institución civil o política) originando una deliberación interior de tipo ético o una deliberación pública de tipo moral o político, respectivamente, pero en ambos casos la acción será práctica y no meramente técnica.

La acción inmanente (opus inmanens, praxis ateles) y la acción transeúnte (opus transihens, poiesis) implicadas en el acto voluntario determinan la distinción clásica entre el obrar (agere) y el producir (facere). No importa que el acto voluntario sea individual o colectivo. El sentido análogo entre uno y otro garantiza con propiedad que las características de uno permanezcan en el otro. De esta forma el acto elícito de la deliberación y la decisión permanecen en la deliberación colectiva, sea propia de una institución civil o política. Pero esta acción política (o teopolítica) 
no se reduce a una acción técnica de razón instrumental (o de razón de Estado) ya que presupone un mundo entorno teopolítico al que debemos adaptarnos para intervenir sobre él. Y este entorno teopolítico como circunstancia y consecuencia de la verdad práctica no denota simplemente un material de trabajo, como en la actividad técnica, sino a otros sujetos racionales que, además de deliberar, también realizan exteriormente lo que han decidido previamente.

Será precisamente la labor crítica de la teología política académica la que nos suministre el mapamundi completo, aunque cambiante, que este mundo teopolítico va adoptando, en parte modificado por las posibilidades de transformación práctica que nos ofrece su sistematización. Porque a diferencia de la moral, en la que la acción práctica se agota en la consolidación del vínculo grupal interhumano, la coexistencia teopolítica está circunscrita a cierto territorio, a áreas de difusión cultural delimitadas por una trayectoria histórica común, de modo que el ámbito de la coexistencia teopolítica está particularizado y exige determinar las diferencias y las incompatibilidades con las otras facciones teopolíticas. Cada plataforma teopolítica realmente existente preexiste al acto deliberativo, siendo condición de posibilidad de la deliberación individual o colectiva. Como presupuesto pragmático más básico de toda comunicación política o moral, la publicidad de esta teología política general se convierte en fundamento de cualquier normatividad posterior. Ningún individuo ni institución civil o política podría desenvolverse adecuadamente por el mundo si no es en relación con quienes le han precedido y con quienes están en condiciones de proseguir la construcción de ese mundo teopolítico, pues solo esa teología política general es capaz de generar reglas válidas y eficaces para la acción teopolítica.

Ni siquiera la nueva teología política inaugurada por Johann Baptist Metz posee esta capacidad de integrar ambas dimensiones de la racionalidad, aun cuando sea la teología política que ha reivindicado del modo más expreso y metódico estas implicaciones prácticas. El propio Metz consideraba que su propuesta, en cuanto «teología práctica fundamental», era una teología política del sujeto cuyo principal cometido era la construcción del éthos verdaderamente humano ${ }^{76}$. "Cuando un status $q u o$ social contiene tanta injusticia como la que eventualmente puede surgir, cuando es suprimido revolucionariamente, entonces una revolu-

${ }^{76}$ Johann Baptist Metz, La fe, en la historia y la sociedad: esbozo de una teología política fundamental para nuestro tiempo (Madrid: Ediciones Cristiandad, 1979), 60-95. 
ción en favor de la justicia y de la libertad de los más pequeños entre los hermanos puede no ser ilícita, incluso en nombre de ese amor» ${ }^{77}$. Bajo la influencia de su magisterio Wolfhart Pannenberg ${ }^{78}$ y Jürgen Moltmann ${ }^{79}$ aproximaron la teología moral a la teología política para afinar su crítica a la subjetividad moderna que deriva de la privatización burguesa de la religión, derivada a su vez de la teología política de la Restauración europea. Esto desembocó en toda una reflexión acerca de las dimensiones éticas de la disciplina, sus posibilidades y su alcance.

Pese a los aciertos y contribuciones valiosas de esta corriente, las aporías denunciadas por sus adversarios pusieron de relieve la limitación inherente a su planteamiento. No obstante, tanto uno como otros consiguieron poner de relieve la importancia que la dimensión práctica posee para una teología política que se precie de serlo. Dado que la nueva teología política ha sido hasta la fecha el planteamiento académico más elaborado en torno a las cuestiones prácticas de la disciplina, resultaba necesario proponer una reorganización sistemática del campo capaz no solo de superar las mencionadas aporías en que incurre, sino también para asumir sus planteamientos y los de sus adversarios. Esta teoría sistemática capaz de integrar sin anomalías las dimensiones teóricas y prácticas de la teología política es precisamente lo que nos hemos propuesto formular en este artículo.

77 Johann Baptist Metz, Teología del mundo (Salamanca: Sígueme, 1971), 157.

78 Cfr. Wolfhart Pannenberg, Teología y Reino de Dios (Salamanca: Sígueme, 1974).

79 Jürgen Moltmann, Teología de la esperanza (Salamanca: Sígueme, 1968), 393408. Ibid., "Historia de la existencia e historia del mundo. Hacia una hermenéutica política del Evangelio", en Esperanza y planificación del futuro (Salamanca, Sígueme, 1971), 215-244. 


\section{BIBLIOGRAFÍA}

Assmann, Hugo. Teología desde la praxis de la Liberación. Salamanca: Sígueme, 1973.

Bueno, Gustavo. Cuestiones cuodlibetales sobre Dios y la religión. Madrid: Mondadori, 1989.

- Primer ensayo sobre las categorías de las ciencias políticas. Logroño: Biblioteca Riojana, 1991.

—. "España”. El Basilisco 24 (1995): 27-50.

-. España frente a Europa. Barcelona: Alba Editorial, 1999.

Böckenförde, Wolfgang-Ernst. State, Society and Liberty: Studies in Political Theory and Constitutional Law. New York: Berg, 1991.

Boff, Clodovis. Teología de lo político. Sus mediaciones. Salamanca: Sígueme, 1980.

Corral Salvador, Carlos y Dalmacio Negro Pavón. “¿Es de verdad posible hoy una Teología Política?”. Revista General de Derecho Canónico y Derecho Eclesiástico del Estado-IUSTEL 17 (2008): 1-7.

Corral Salvador, Carlos. Teología política. Una perspectiva histórica y sistemática. Valencia: Tirant, 2011.

d'Ors, Álvaro. "El Glossarium de Carl Schmitt". En Estudios sobre Carl Schmitt, editado por Dalmacio Negro Pavón, 17-48. Madrid: Fundación Cánovas del Castillo, 1996.

Dabezies, Pablo y Benoit A. Dumas. Teología de la violencia. Salamanca: Sígueme, 1970.

Dussel, Enrique. “Teología de la liberación y marxismo”. En Mysterium liberationis. Conceptos fundamentales de la teología de la liberación, editado por Ignacio Ellacuría y Jon Sobrino. Vol. I, 138-159. Madrid: Trotta, 1990.

-. Política de la liberación II. Madrid: Trotta, 2009.

Freund, Julien. La esencia de lo político. Madrid: Editora Nacional, 1968.

-. Sociología del conflicto. Madrid: Ministerio de defensa, 1995.

Galli, Carlo. "Le teologia politische di Carl Schmitt". En Democrazie e religioni, editado por M. Ruggenini, 334-347. Roma: Donzelli, 2012.

Gollwitzer, Helmut. Crítica marxista de la religión. Madrid: Marova, 1971. González Montes, Adolfo. "Las aporías de la teología crítica: Sobre algunos estudios recientes". Salmanticensis Vol. 29, Fasc. 3 (1982): 425-442. 
—. Teología política contemporánea. Historia y sistemas. Salamanca: PUPS, 1995.

Gutiérrez, Gustavo. Teología de la liberación. Perspectivas. Salamanca: Sígueme, 1972.

Kantorowicz, Ernst Hartwig. Los dos cuerpos del rey: un estudio de teología política medieval. Madrid: Akal, 2012.

Lehmann, Karl. "Die politische Theologie: Theologische Legitimation und gegenwärtige Aporie”. En Essener Gespräche. Tomo IV. Münster, 1969.

-. "Aporías actuales de la teología política". Selecciones de Teología política, 38 (1971): 267-301.

Lochmann, Jan Milic. Perspektiven politischer Theologie. Zürich: TVZ Verlag, 1971.

Maier, Hans. Kritik der Politischen Theologie. Einsiedeln: Verlag, 1970.

Metz, Johann Baptist. "La teología política en discusión”. Selecciones de Teología 38 (1971): 98-118.

-. Dios y tiempo. Nueva teología política. Madrid: Trotta, 2002.

-. La fe, en la historia y la sociedad: esbozo de una teología política fundamental para nuestro tiempo. Madrid: Ediciones Cristiandad, 1979.

-. Teología del mundo. Salamanca, Sígueme: 1971.

Míguez Bonino, José. La fe en busca de eficacia: una interpretación de la reflexión teológica latinoamericana de liberación. Salamanca: Sígueme, 1977.

Moltmann, Jürgen, "Historia de la existencia e historia del mundo. Hacia una hermenéutica política del Evangelio". En Esperanza y planificación del futuro, 215-244. Salamanca: Sígueme, 1971.

—. "Crítica teológica a la religión política". En Ilustración y teoría teológica. La Iglesia en la encrucijada de la libertad moderna. Aspectos de una nueva teología política, editado por J. B. Metz, J. Moltmann y W. Oelmüller, 11-45, Salamanca: Sígueme, 1973.

-. El Dios crucificado. Salamanca: Sígueme, 1977.

-. Teología de la esperanza. Salamanca, Sígueme, 1968.

- Teología política. Ética política. Salamanca: Sígueme, 1984.

Negro, Dalmacio. “¿Por qué no la teología política?”. En Estudios sobre la Centessimus Annus, coordinado por F. Fernández Rodríguez, 249294. Madrid: AEDOS-Unión Editorial, 1992.

Nicoletti, Michele. Trascendenza e potere: la teologia politica di Carl Schmitt. Brescia: Morcelliana, 1990. 
Pannenberg, Wolfhart. "Geschichtstatsachen und christliche Ethik. Zur Relevanz geschichtlich-politischer Sachfragen für die christliche Ethik, 2. Veröffentlichung". En Diskussion zur politischen Theologie, editado por Helmut Peukert, 231-246. Mainz-München: Matthias Grünewald, 1969.

—. Teología y Reino de Dios. Salamanca: Sígueme, 1974.

Peña Eguren, Esteban. La filosofía política de Guillermo de Ockham. Relación entre potestad civil y potestad eclesiástica. Madrid: Encuentro, 1994.

Rendtorff, Trutz. "Politische Ethik oder politische Theologie?". En Diskussion zur politischen Theologie, editado por Helmut Peukert, 217230. Mainz-München: Matthias Grünewald, 1969.

Schillebeeckx, Edward. El mundo y la Iglesia. Salamanca: Sígueme, 1970.

Schmitt, Carl. El Leviathan en la teoría del estado de Tomas Hobbes. Madrid: Comares, 2003.

—. Glossarium. Aufzeichnungen Der Jahre 1947-1951. Berlin: Dunker und Humboldt, 1991.

Schoonbrood, Michel. "Praxis social y referencia a Jesucristo". En Práctica de la Teología Política, dirigido por Marcel Xhaufflaire et al, 65101. Salamanca: Sígueme, 1978.

Spaemann, Robert. "Teología, profecía y política. Hacia una crítica de la teología política”. Selecciones de Teología 38 (1971): 175-183.

-. Crítica de las utopías políticas. Pamplona: EUNSA, 1980.

Wiedenhofer, Siegfried. Politische Theologie. Stuttgart: Kohlhammer, 1976.

Xhaufflaire, Marcel. La teología política. Salamanca: Sígueme, 1974. 